\title{
EFETIVIDADE DO DIREITO HUMANO À ALIMENTAÇÃO ADEQUADA EM TEMPOS DE PANDEMIA: INCERTEZAS E INCOERÊNCIAS
}

\author{
Regina Vera Villas Bôas ${ }^{1}$ \\ Durcelania da Silva Soares ${ }^{2}$
}

\begin{abstract}
Resumo: O presente artigo analisa o direito humano à alimentação adequada, em tempos de pandemia, e as incertezas e incoerências quanto a efetividade desse direito, trazendo à discussão o risco de se consolidar no mundo uma "pandemia de fome", dobrando o número de pessoas na situação de fome aguda. Vivencia-se, assim, a tragédia pandêmica de COVID-19 e, essa crise econômica e sanitária traz como consequência a brutal violação do direito humano à alimentação adequada, o qual vem se mostrando como um dos direitos fundamentais mais atingidos, juntamente com o direito à saúde e à vida.
\end{abstract}

Palavras-chaves: Direito humano à alimentação adequada; efetividade dos direitos fundamentais; pandemia de COVID-19; fome.

\section{EFFECTIVENESS OF THE HUMAN RIGHT TO ADEQUATE FOOD IN PANDEMIC TIMES: UNCERTAINTIES AND INCOHERENCES}

\begin{abstract}
This article analyzes the human right to adequate food, in times of pandemic, and the uncertainties and inconsistencies regarding the effectiveness of this right, bringing to the discussion the risk of consolidating a "hunger pandemic" in the world, doubling the number of people in the situation of acute hunger. Thus, the pandemic tragedy of COVID-19 is experienced and this economic and sanitary crisis has as a consequence the brutal violation of the human right to adequate food, which has been showing itself as one of the most affected fundamental rights, together with the right health and life.
\end{abstract}

Keywords: Human right to adequate food; effectiveness of fundamental rights; COVID-19 pandemic

\section{INTRODUÇÃO}

\footnotetext{
${ }^{1}$ Bi-Doutora em Direito das Rel. Sociais e em D. Difusos e Coletivos, Mestre em Direito das Rel. Sociais, todos pela Pontifícia Universidade Católica de São Paulo. Pós-Doutora em Democracia e D. Humanos pela Univ. de Coimbra - Portugal ("Ius Gentium Conimbrigae"). Coordenadora do JEC (PUC/SP); Prof. e invest. nos PPGs na PUC/SP. Integrante do PP Efetividade dos DH e DF: Diálogo das Fontes (PUC/SP). http://lattes.cnpq.br/4695452665454054/ E-mail: revillasboas1954@gmail.com, https://orcid.org/0000-0002-3310-4274.

2 Mestre em Direito pela UNISAL. Docente na Universidade Estácio de Sá - RJ. E-mail: durcelania@hotmail.com. http://lattes.cnpq.br/1543810316645867
} 
O presente trabalho reflete sobre as ações propostas em tempos de pandemia de COVID-19, no que diz respeito a (in)efetividade do Direito Humano à Alimentação Adequada diante à ausência de políticas públicas que assegurem a alimentação, dificultando a efetividade da inclusão dos vulneráveis socioeconômicos.

Reflete-se, sob o prisma da efetividade, a respeito do direito humano à alimentação (adequada), objetivando verificar a atual situação da política de segurança alimentar e nutricional, no enfrentamento da fome e se, de fato, tem efetivado a concreção do direito humano à alimentação adequada, no período de pandemia de COVID-19.

A pandemia de COVID-19 assola o mundo, desde o início do ano de 2020, e persiste até os dias atuais, principalmente em países que, igualmente ao Brasil, não possui previsão de vacinação em massa - tratamento comprovadamente eficaz no combate a pandemia. Atualmente, o mundo passa por uma crise econômica e sanitária e, nestas crises, a consequência consagrada é a de que o direito humano à alimentação adequada (DHAA), juntamente com o direito à saúde e à vida se transformam nos direitos fundamentais mais brutalmente violados.

Para atingir o objetivo proposto, o texto foi dividido em duas seções, objetivando apresentar em um primeiro momento, a temática "fome", apontando o enfraquecimento da efetividade deste direito, e o desenvolvimento de políticas públicas do Estado, voltadas à satisfação das necessidades prioritárias dos mais vulneráveis. Em derradeiro momento, volta a discussão às incertezas quanto à efetivação do Direito à Alimentação, em tempos de pandemia, apontando o risco da ocorrência de pandemia de fome daqueles que, ainda, até o presente momento, conseguem sobreviver aos efeitos pandêmicos, que são devastadores.

A relevância da pesquisa se justifica pela atualidade e especificidade do tema investigado, o qual aponta necessidade de debates sobre referida problemática a ser enfrentada pela sociedade civil, intermediada, também, por movimentos sociais, que lutam incessantemente pela concretização do direito humano à alimentação (adequada), buscando garantir direitos, notadamente, dos mais vulneráveis econômica e socialmente.

Foi utilizado na construção do presente texto, o método de investigação dialético, desenvolvido por pesquisa bibliográfica, documental e eletrônica. Os dados coletados têm origem em fontes como livros, periódicos qualificados, revistas e sites especializados que trazem posições importantes sobre organizações internacionais, relacionadas à matéria. 


\section{FOME E ALIMENTAÇÃO EM UMA PERSPECTIVA DELIMITADORA}

No cenário atual nacional e global, destaca-se a necessidade da abordagem sobre a fome, não obstante o crescimento da produção alimentícia no Brasil e no mundo. De acordo com a OMC, o Brasil é o $3^{\circ}$ maior exportador de produtos agropecuários do mundo. Só fica atrás dos EUA e da União Europeia. O país ocupa o $1^{\circ}$ lugar na exportação de diversos grupos de alimentos. Só no ano de 2008, as exportações de alimentos produzidos no Brasil chegaram a US\$ 61,4 bilhões, e em 2016 o Brasil terminou o ano com uma fatia de 5,7\% do mercado global, abaixo somente dos Estados Unidos, com 11\%, e Europa, com 41\% (CHADE, 2018).

Todavia, mesmo diante desse avanço das exportações de produtos alimentícios, o Brasil vive em um quadro de insegurança alimentar e nutricional. Conforme pesquisa do IBGE (2013), em cada quatro lares brasileiros, um vive algum grau de insegurança alimentar, registrando-se que, no ano de 2013, 52 milhões de pessoas, residentes em 14,7 milhões de domicílios, apresentavam alguma restrição alimentar ou, pelo menos, alguma preocupação com a possibilidade de ocorrência de restrição em relação à falta de recursos para adquirir alimentos.

No nível mundial, o Fundo das Nações Unidas para a Infância (UNICEF) lançou um alerta, no ano de 2017, indicando que um milhão e quatrocentas mil crianças, enfrentariam o risco de morrer de fome, em quatro países: Iêmen, Nigéria, Somália e Sudão do Sul, este último declarando, oficialmente, ter sido atingido por um "surto de fome" (GARCIA, 2017, p. $1)$.

E sobre a fome, André Mayer ao prefaciar a nona edição do livro Geografia da fome, de Josué de Castro, destaca: "A fome - eis um problema tão velho quanto a própria vida". (CASTRO, 1984, p. 6). Esse problema tão antigo coloca em risco a vida, a própria sobrevivência da espécie humana até os dias atuais. Há tempos se vem buscando alternativas para solucionar esse "problema tão velho", mas que está tão presente nos novos dias.

No afã de se encontrar alguma solução viável para a redução da fome, houve o aumento da produção agrícola e agropecuária. Em contrapartida, a fome continua a existir atualmente, o que leva a crer que na problemática da fome não está adstrita apenas à produção de alimentos. Para Jean Ziegler (2013), “[...] não há escassez de alimentos. O problema da fome é o acesso à alimentação". A especulação financeira dos alimentos, como commodities, 
nas bolsas de valores, é um dos principais fatores para o crescimento dos preços da cesta básica nos últimos anos. Esta é uma das principais causas da falta de acesso aos alimentos, causando, por conseguinte, a fome (RIBAS, 2011, p. 2).

A produção capitalista aumentou ao ponto de dobrar, no ano de 2002, produção esta que seguiu processo de monopolização de riquezas. Hoje, 52,8\% do PIB mundial está nas mãos de empresas multinacionais, sendo que a concentração de $85 \%$ dos alimentos negociados no mundo, encontra-se nas mãos de apenas 10 empresas, fazendo com que esses agentes tenham grande força política. O poder político dessas empresas foge ao controle social. Elas decidem, dia-a-dia, quem vai comer e quem vai morrer de fome. (ZIEGLER, 2013b).

"A história da humanidade é, em grande parte, a história da luta contra a fome". (MARANHÃO, 1962, p. 75). O fenômeno da fome é antigo e universal e a morte atinge, até os dias atuais, milhões de pessoas. Por mais absurdo que possa parecer, a fome não pode ser erradicada, pois integra o sistema econômico, e "[...] vale a regra de que quem tem dinheiro tem bens e serviços, a alimentação agora, ou é bem ou é serviço; não é mais sobrevivência". (MARANHÃO, 1962, p. 5). Nesse sentido, a cadeia alimentar humana está nas mãos de um pequeno grupo de grandes produtores.

A definição de fome é um bastante controversa. A discussão acerca desse fenômeno baseia-se nas denúncias apresentadas por Josué de Castro, quando investigou a temática, nos anos de 1940, tendo como principal causa da fome, a falta de alimentos, principalmente nos países que haviam perdido a Segunda Guerra Mundial (CASTRO, 1984, p. 48). "Na realidade, a fome coletiva é um fenômeno social bem mais generalizado. É um fenômeno geograficamente universal, não havendo nenhum continente que escape à sua ação nefasta". (PODESTÁ, 2011, p. 72).

Rangel (2018a, p. 42) nos orienta que o problema da fome se concentra nas escolhas políticas, assim afirmando

No território nacional, admitia-se a fome como um problema do meio ambiente, da raça, da indolência da população. [...] a fome é fruto das escolhas de desenvolvimento às quais está subordinada a sociedade brasileira, tendo como causa as escolhas políticas, é o resultado das macrodecisões sociais e econômicas que compreendem o destino alimentar de milhões de brasileiros.

A fome necessariamente está ligada à questão sociopolítica, não só no Brasil como no mundo. Governantes que se preocupam com o seu povo buscam alimentá-los; do contrário, 
o escravizam para que sirvam de massa de manobra. As escolhas sociopolíticas se transformam em políticas públicas que podem se voltar às desigualdades sociais, e não ao bem-estar da sociedade.

Para Tânia Elias Magno da Silva (2009, p. 52) a fome é um dos retratos mais cruéis de intolerância, principalmente aquela que se perpetua em tempos de abundância proveniente do desperdício e da ganância, que mata lentamente, enganando os famintos, já que apenas enche os seus estômagos, no lugar de alimentá-los.

Sobre a fome, Maria do Carmo Soares de Freitas (2003, p. 38) esclarece que

\begin{abstract}
A sensação de fome de um é distinta da de um outro também faminto, mesmo que haja "algo" comum entre eles, porque as coisas do mundo não se impõem ao homem de uma forma linear, causal e impositiva. O que é percebido num momento, pode ser alterado e percebido de outra maneira, num momento seguinte. Sendo assim o significado da fome perpassa a imagem corpórea da carência de comida, indo ao encontro de outras concepções sustentadas por um sistema de símbolos gerados pela insegurança concreta de alimentar-se.
\end{abstract}

Entre as diversas facetas da fome, é preciso atentar para o faminto e não apenas para o fenômeno fome, pois esse faminto apresenta característica diversa de um para o outro. Basta atentar à percepção de fome entre pessoas com características diferenciadas, como o fato da idade, do sexo e dos hábitos alimentares. O sentimento de fome de um adolescente é diferente do sentimento de fome de um homem adulto, porém tudo é fome e deve ser combatido, devendo ser preservado o direito de todos a não suportar tal mal.

Ainda nessa temática, Nascimento (2012, p. 51-52) destaca que o fenômeno fome é uma trágica expressão de desenvolvimento dos países ricos, que se sustentam na exploração de países mais pobres, e provoca uma fome quantitativa, aguda, mas também qualitativa ou oculta.

Há uma distinção entre a fome aguda, que é a urgência de se alimentar e a fome crônica, que é a deficiência energética, a desnutrição, o que é explicado por Rangel (2018a, p. 44), ao afirmar que

A fome aguda, também denominada de total, global ou quantitativa, seria aquela menos comum e mais fácil de ser verificada. Com efeito, faz referência à verdadeira inanição, limitado a áreas de extrema miséria e a contingências excepcionais. Já a outra espécie de fome, denominada de fome crônica, também nomeada de parcial, qualitativa ou latente, materializa um fenômeno mais frequente e mais grave. A falta contínua de determinados elementos nutritivos, nos regimes alimentares habituais dos povos subdesenvolvidos, e até de uma pequena parcela dos desenvolvidos, provoca 
a morte lenta de vários grupos humanos no planeta, apesar de comerem todos os dias.

A fome aguda é aquela fome que incomoda a todos, pois é vista a olho nu, caracterizando-se pela falta de alimentação, normalmente encontrada junto à extrema miséria, associada à pobreza extrema, pois o faminto não tem como se alimentar. Para aplacar essa fome, é necessário que o Estado dê a alimentação a essas pessoas para retirá-las desse estado extremista. Neste momento, segundo Castro (2003, p. 79-80), o homem se apresenta como um animal de rapina, possuindo um único desejo: comer, como afirma Rangel (2018a, p. 45),

\begin{abstract}
A fome crônica é mais perversa que a forma global, determinada pela incapacidade de alimentação diária em fornecer um total calórico correspondente ao gasto energético realizado pelo trabalho do organismo, porquanto atua de maneira sorrateira, sem que a população afetada perceba seu malefício. Ela é caracterizada pela ausência ou presença em quantidades exageradas de certas substâncias alimentares, a exemplo de sais minerais, vitaminas, proteínas e gorduras. Essa fome decorre de uma má alimentação, representando o aspecto qualitativo da questão, justamente nesse aspecto das fomes parciais, em sua infinita variedade.
\end{abstract}

Nascimento (2012, p. 52) descreve que, o ser humano, “[...] por meio dos tempos, sacrificou pouco a pouco a variedade pela quantidade, restringindo o abastecimento regular das coletividades às substâncias de maior rendimento alimentar e de produção e conservação relativamente mais fáceis".

A fome crônica é considerada como "fruto de nossa própria civilização". (NASCIMENTO, 2012, p. 52). É aquela que se caracteriza pela qualidade de alimentos ingeridos, decorrente de uma má alimentação, desprovida dos nutrientes necessários ao desenvolvimento sadio do ser humano. É a fome fabricada, pois quando se tem os alimentos, esses não são de qualidade para atender às necessidades nutricionais do ser humano que os consome, sendo privado dos nutrientes, que resulta na desnutrição, e que por sua vez decorre da inadequação alimentar, que abrange aspectos quantitativos e qualitativos.

Necessário esclarecer que a Organização Mundial de Saúde (OMS) fixa em 2.200 calorias diárias o mínimo vital para um adulto. Certo é que as necessidades calóricas irão variar de acordo com a idade da pessoa, sendo 700 calorias diárias para um lactente, 1.000 calorias para um bebê entre um e dois anos, 1.600 calorias para uma criança de cinco anos e entre 2.000 a 2.700 calorias para um adulto, dependendo do clima em que vive e do trabalho desempenhado por esse adulto (ZIEGLER, 2013a, p. 32). Uma pessoa adulta que ingere menos de 2.000 calorias diárias certamente não irá reproduzir de forma satisfatória a sua força 
vital. Ficará comprometido o desenvolvimento de suas tarefas diárias, como a desenvolvida para a sua própria subsistência. Sem ingerir tais calorias, um adulto não conseguirá desempenhar suas tarefas de forma satisfatória.

No que tange à subalimentação, Jean Ziegler (2013a, p. 32) assevera que

\begin{abstract}
A subalimentação severa e permanente provoca um sofrimento agudo e lancinante do corpo. Produz letargia e debilita gradualmente as capacidades mentais e motoras. Implica marginalização social, perda de autonomia econômica e, evidentemente, desemprego crônico pela incapacidade de executar um trabalho regular. Conduz inevitavelmente à morte.
\end{abstract}

Certamente a subalimentação provoca no ser humano a destruição de seu corpo e de seu psiquismo, o que vai levar necessariamente à decadência física, já que não haverá possibilidade de empregar um ser subalimentado (ZIEGLER, 2013, p. 33). E, sem condições de se manter física e psiquicamente, estará à margem da sociedade, enfrentando o risco de morrer de fome. Anota-se que a subalimentação leva à morte silenciosa.

Além da subalimentação, vale mencionar a subnutrição, que também pode levar à morte. Em geral, a subnutrição pode ser causada pela alimentação deficiente ou pela falta de alimentos. Quanto à alimentação deficiente, é aquela alimentação que mata a fome, mas não fornece os elementos essenciais para o bom funcionamento do organismo. Na subnutrição, a ingestão alimentar regular não chega a cobrir as necessidades energéticas mínimas da pessoa, e, de acordo com o relatório sobre o estado da insegurança alimentar no mundo 2012, quase 870 milhões de pessoas sofrem subnutrição crônica no mundo (ONUBR, 2012).

Sen (2010) ensina que a pobreza e, em consequência, a fome privam o indivíduo de suas capacidades básicas e, sobretudo, de sua liberdade. E acrescenta: "O que faz dessa fome disseminada uma tragédia ainda maior é o modo como acabamos por aceitá-la e tolerá-la como parte integrante do mundo moderno". (SEN, 2010, p. 264). A fome não pode ser um fato essencialmente inevitável. Tem que ser combatida, enfraquecida e banida. É preciso capacitar os indivíduos para que se possa enfrentar a fome, assegurando a liberdade e o direito a todos de viver sem experimentar a fome.

É necessário o enfraquecimento da fome, enfraquecendo as desigualdades sociais, e para isso o Estado deve desenvolver e efetivar políticas públicas voltadas à satisfação das necessidades dos mais carentes. O Estado deve facilitar, nesse sentido, uma melhor distribuição de rendas e um maior acesso de todos aos bens e serviços públicos, dando 
celeridade às inclusões sociais, combate às desigualdades sociais e efetivamente capacitando os famintos e não os privando de sua liberdade de sobreviver livre da fome.

\section{INCERTEZAS NA EFETIVAÇÃO AO DIREITO À ALIMENTAÇÃO EM TEMPOS DE PANDEMIA DE COVID-19}

O ano de 2020 inicia-se de uma forma atípica, já que em 30 de janeiro a Organização Mundial da Saúde (OMS) declara a doença causada pelo novo coronavírus (COVID-19) como Emergência de Saúde Pública de Importância Internacional. De acordo com o Regulamento Sanitário Internacional (RSI), do qual o Brasil é signatário, o mais alto nível de alerta da Organização e, não por acaso, no dia 11 de março de 2020, a COVID-19 foi caracterizado pela OMS como uma pandemia. A doença cresceu em quantidade inesperada, por várias regiões do planeta, em diferentes continentes, com transmissão local fixada. (PELLANDA, 2020).

Em três de fevereiro de 2020, o Ministério da Saúde declarou Emergência de Saúde Pública de Importância Nacional (ESPIN) em decorrência da infecção humana pelo novo Coronavírus (COVID-19), por meio da Portaria MS n 188. Referida Portaria estabelece o Centro de Operações de Emergências em Saúde Pública (COE-COVID-19) como mecanismo nacional da gestão coordenada à emergência no âmbito nacional, ficando sob responsabilidade da Secretaria de Vigilância em Saúde (SVS/MS) a gestão do COE-COVID19. (BRASIL, p. 9, 2020)

Diante da Emergência em Saúde Pública declarada pela Organização Mundial da Saúde (OMS), em janeiro de 2020, por doença respiratória causada pelo COVID-19, e seguindo as recomendações da OMS, o Ministério da Saúde elaborou o Plano de Contingência Nacional para Infecção Humana pelo novo Coronavírus (COVID-19) em caso de surto, avaliando o risco do novo Coronavírus afetar o Brasil e seu impacto para a saúde pública. Naquele momento a Secretaria de Vigilância em Saúde destaca que

até o momento, fatos e conhecimentos sobre o novo coronavírus (COVID19) disponíveis são limitados. Há muitas incertezas no modo exato de transmissão e os possíveis reservatórios. As taxas de letalidade, mortalidade e transmissibilidade não são definitivas e estão subestimadas ou superestimadas. As evidências epidemiológicas e clínicas ainda estão sendo descrita e a história natural desta doença está sendo construída. As 
informações cruciais para apoiar avaliação dos fatores mencionados, como infectividade, transmissibilidade, taxa de complicações, letalidade, mortalidade, serão gradualmente disponibilizadas. (FERNANDES, 2020).

Assim, a partir daquele momento uma série de ações são adotadas

culminando com a ativação no dia 22 de janeiro de 2020 do Centro de Operações de Emergência em Saúde Pública (COE-COVID-19), do Ministério da Saúde (MS) coordenado pela Secretaria de Vigilância em Saúde (SVS), com o objetivo de nortear a atuação do MS na resposta à possível emergência de saúde pública, buscando uma atuação coordenada no âmbito do SUS. (BRASIL, p. 4, 2020)

No Brasil, a introdução da doença foi uma questão de tempo, e após a decretação da pandemia do coronavirus, devido ao COVID-19, uma das medidas adotadas para evitar a dispersão do vírus, a transmissão de pessoa a pessoa, foi o intenso apelo para que a população ficasse em isolamento socia, evitando o caos do Sistema Único de Saúde, sob o argumento de que não haveria leitos suficientes ao atendimento de enorme demanda de vítimas da doença.

As medidas adotadas pelo Planos de Contingência Nacional para Infecção Humana pelo novo coronavírus COVID-19, objetivando evitar a ocorrência de casos graves e óbitos, afirmava

\footnotetext{
Assim, medidas de atenção hospitalar para os casos graves e medidas restritivas individuais de isolamento e quarentena domiciliar para os casos leves, devem ser adotadas para evitar óbitos e o agravamento dos casos.

Esse fortalecimento da atenção PRIMÁRIA ao paciente deve ocorrer no nível local, com a adoção das medidas já estabelecidas nos protocolos de doenças respiratórias.

Adicionalmente, caso seja evidenciada a possibilidade de superação da adaptação e ampliação de leitos e áreas hospitalares e a contratação emergencial de leitos de UTI pode ser necessária, com o objetivo de evitar óbitos (BRASIL, p. 7, 2020).
}

Um ano após o início da pandemia, em março de 2021, o Brasil contabiliza um acúmulo de mais de 325 mil óbitos (BRASIL, 2021), indicando questão de ordem pública, diante da omissão do poder estatal na implementação de políticas públicas, efetivas, na área da saúde e na área da alimentação em tempos de pandemia.

No ano de 2019 o relatório da Organização das Nações Unidas para a Alimentação e a Agricultura (FAO, 2021) já sinaliza que no mundo muitas pessoas estariam sofrendo com a fome, cerca de 820 milhões, e que 2 bilhões estariam vivendo em algum grau de insegurança alimentar. 
No Brasil, a situação da fome se agrava de forma considerável com a pandemia de COVID-19, a pandemia está em total descontrole, afeta a saúde, a educação, a economia e a alimentação daquela população que vive em situação de vulnerabilidade, já que não conseguem apoio financeiro do governo para poder conseguir comida para aplacar a fome. Por sua vez o Brasil que ,em 2014, havia saído do Mapa Mundial da Fome, voltará a compor referida lista.

De acordo com relatório publicado em 2020, durante a pandemia da COVID-19, pelo Programa Mundial de Alimentos (PMA, 2020), maior agência humanitária do mundo, que fornece uma média de alimentos para 90 milhões de pessoas distribuído em 80 países, anualmente, informa o risco de se consolidar uma pandemia de fome que pode dobrar o número de pessoas em situação de fome aguda no mundo, tendo em vista a crise sanitária provocada pela pandemia da COID-19. Trata-se agora do risco de uma pandemia de fome daqueles que ainda estão conseguindo sobreviver à pandemia desse devastador vírus.

Os números mais recentes indicam que a vida e o sustento de 265 milhões de pessoas em países de baixa e média renda estarão sob grave ameaça, comparado com 135 milhões de pessoas no ano de 2019, por isso é necessário que sejam tomadas medidas rápidas para combater a pandemia, os declínios na atividade econômica provavelmente diminuirão os orçamentos nacionais e das famílias. A situação alimentar pode continuar a piorar, mas a magnitude das consequências, ainda, não é conhecida, no ano de 2019. (ONU, 2021).

De acordo com o OXFAM, o Brasil está entre os prováveis epicentros globais da fome, juntamente com a Índia e a África do Sul.

"A covid-19 é a última gota para milhões de pessoas que já lutam dia após dia com vários impactos em suas vidas. São conflitos armados, mudança climática, desigualdades e um sistema viciado de produção de alimentos", afirma Katia Maia, diretora executiva da Oxfam Brasil."

"Os riscos de disparada da fome no país são imensos quando o Estado brasileiro falha em garantir as condições mínimas de sobrevivência a todas as pessoas impactadas pela pandemia", afirma Maitê Guato, gerente de Programas e Campanhas da Oxfam Brasil. "Não basta criar programas de proteção, o que muda a vida das pessoas é fazer os recursos chegarem na ponta." (OXFAM, 2020).

Em relatório da 'Brookings', do dia 06 de maio de 2020, com a COVID-19, uma em cada cinco crianças nos EUA estão passando fome e a principal razão é a privação do acesso à alimentação escolar, para muitos alunos da rede pública essa alimentação oferecida na escola costuma ser a principal quando não a única forma de acessar os alimentos não só no Brasil 
como em diversos países no mundo. Nestas crises, econômica e sanitária, a consequência é que o direito humano à alimentação adequada (DHAA) é um dos direitos fundamentais mais brutalmente violados. De acordo com Guterres ${ }^{3}$, uma em cada nove pessoas no mundo não tem comida suficiente para se alimentar. Ainda, que cerca de 155 milhões de crianças estão malnutridas e poderão sofrer os efeitos do nanismo ao longo de toda a sua vida. (BAUER, 2020).

No Brasil, esta realidade é uma das principais pautas políticas do Fórum Brasileiro de Soberania e Segurança Alimentar e Nutricional Sustentável, em tempos de COVID-19, pois com a suspensão das aulas por tempo indeterminado em grande parte do país, torna-se imprescindível garantir a segurança alimentar e nutricional dos estudantes, por meio do emprego urgente de medidas de prevenção, controle e contenção de riscos à saúde, objetivando evitar a disseminação da doença, fato este, que vem acontecendo, infelizmente.

O que se tem observado é um crescente número de insegurança alimentar nos lares brasileiros nesse período de pandemia, isso reforçado pela falta de alimentação escolar, pois a grande maioria das crianças que frequentam a escola pública de educação básica necessitam da alimentação ofertada pelas escolas, e em muitos casos essa é a refeição mais importante do dia, quando não a única.

As taxas de insegurança alimentar observadas em abril de 2020 também são significativamente mais altas do que em qualquer ponto para o qual existem dados comparáveis (2001 a 2018). Olhando ao longo do tempo, especialmente para o aumento relativamente pequeno da insegurança alimentar infantil durante a Grande Recessão, fica claro que as crianças pequenas estão experimentando uma situação de insegurança alimentar sem precedentes nos tempos modernos. (BAUER, 2020.)

No início da pandemia ficou evidenciado que "Os recursos do Programa Nacional de Alimentação Escolar (PNAE) estão disponíveis para a distribuição de alimentos, mas ainda são poucos os estados e municípios que fazem a distribuição da Alimentação Escolar." (FBSSAN, 2020), e um dos grandes avanços nessa seara foi a promulgação da Lei n. ${ }^{\circ}$ 13.987, de 7 de abril de 2020, que alterou a Lei no 11.947, de 16 de junho de 2009, e autorizou, em caráter excepcional, durante o período de suspensão das aulas em razão de situação de emergência ou calamidade pública, a distribuição de gêneros alimentícios adquiridos com

\footnotetext{
${ }^{3} 9^{\circ}$ Secretário-Geral da ONU, $14^{\circ}$ Primeiro-Ministro de Portugal e $10^{\circ}$ Alto Comissário das Nações Unidas para os Refugiados.
} 
recursos do Programa Nacional de Alimentação Escolar (PNAE) aos pais ou responsáveis dos estudantes das escolas públicas de educação básica.

Outra medida importante para a efetivação do direito à alimentação no ano de 2020 foi a lei de auxílio emergencial para os trabalhadores informais, microempreendedores individuais, contribuintes individuais da Previdência Social e desempregados, Lei $\mathrm{n}^{\mathrm{o}}$ 13.982/20, mas que teve sua vigência até o final de 2020. Estabelecia medidas excepcionais de proteção social que seriam adotadas durante o período de enfrentamento da emergência de saúde pública de importância internacional decorrente do coronavírus (COVID-19) responsável pelo surto de 2019. No Brasil o surto só fez aumentar, com o diferencial que agora a ajuda do Governo está bastante limitada já que a lei não vigora como anteriormente instituída e essa adequação para desfavorecer, claramente viola o direito à alimentação dessa população carente e faminta que vive em vulnerabilidade socioeconômico.

É necessário observar que essas ações inviabilizam o acompanhamento do progresso em direção ao Objetivo de Desenvolvimento Sustentável 2, Fome Zero, que visa acabar com a fome, promover a segurança alimentar e acabar com todas as formas de má nutrição até 2030.

Isto significa dizer que o mundo está longe de alcançar a meta do Objetivo de Desenvolvimento Sustentável (ODS) de erradicar a pobreza e a fome de maneira sustentável, até o ano de 2030, erradicação esta, relacionada a todas as formas e dimensões de pobreza, incluindo a pobreza extrema, que é o maior desafio global e, requisito indispensável ao desenvolvimento sustentável.

A agenda 2030 para o desenvolvimento sustentável (ONUBR, 2018) busca, por meio da meta da ODS libertar a raça humana da tirania da pobreza e da penúria com a erradicação da fome no mundo. São medidas ousadas, transformadoras e necessárias. A agenda universal é ambiciosa, contudo, necessária. Os referidos objetivos buscam a concretização dos direitos humanos de todos, alcançando a igualdade de gênero e o empoderamento das mulheres e das meninas, buscando exterminar a pobreza em todas as suas formas e lugares, acabando com a fome e alcançar a segurança alimentar com a melhoria da nutrição, promovendo-se a agricultura sustentável.

Contudo, o fenômeno fome está longe de ser erradicado, pois a “[...] a fome é um flagelo fabricado pelos homens contra outros homens" (MELLO; NEVES, 2007, p. 8), e não propriamente a falta de alimentos. Pode-se dizer que a fome se relaciona com a capacidade que tem o homem e adquirir o seu próprio sustento, devendo o Estado capacitá-lo e garantir- 
lhe a concretização do Direito Humano à Alimentação Adequada, afastando-os da pobreza extrema.

Não há dúvidas de que, em qualquer parte do mundo, a pobreza é entendida como a ausência ou a privação de uma necessidade básica do ser humano, oscilando, muitas vezes, quanto à intensidade desta privação. A falta de rendimentos impede que o indivíduo se alimente e, sendo a alimentação a primeira condição básica à sua sobrevivência, caso não efetivada, poderá ocasionar o seu estado de indigência e, também, a sua morte (VILLAS BÔAS e SOARES, 2017, p.80).

\section{CONCLUSÃO}

O presente trabalho teve por destinação analisar o as incertezas no que tange a efetivação do Direito Humano à Alimentação Adequada no enfrentamento à fome e verificar se de fato o direito humano à alimentação adequada está sendo concretizado, sob o prisma da dignidade da pessoa humana, em tempos de pandemia.

Restou demonstrado que o direito humano à alimentação adequada, mesmo como obrigação fisiológica primordial ao desenvolvimento humano, ainda hoje é um dos direitos mais violados pelo Estado. Note-se que a Declaração Universal dos Direitos Humanos, de 1948, foi o primeiro documento internacional do século XX a prever tal direito, acompanhado posteriormente por outros documentos internacionais (tratados, convenções e pactos) que repetem a previsão do direito à alimentação, como o Pacto Internacional sobre os Direitos Econômicos, Culturais e Sociais de 1966 que, de maneira expressa, no artigo 11, dispõe sobre o direito à alimentação, com o seu alargamento, incluindo o direito humano à água, bem como o artigo $6^{\circ}$ da Constituição da República Federativa do Brasil.

Um dos maiores desafios à concretização do direito humano à alimentação adequada, é o respeito à diversidade cultural, e em tempos de pandemia é necessário a continuidade da prestação de alimentos nas escolas públicas às crianças, jovens e adolescentes, focando ainda, que a descontinuidade da prestação dos benefícios a parcela da população em situação de vulnerabilidade só aumenta a insegurança alimentar revelando que, de fato, o Direito Humano à Alimentação Adequada no contexto da vida saudável, em tempos de pandemia COVID-19 não está sendo materializado e que todos já vivem uma pandemia de fome. 
Ademais, os grupos dotados de maior vulnerabilidade e marginalizados tendem a ser afetados diretamente pela atuação omissa do Estado no processo de internalização dos direitos humanos. O direito à alimentação centra-se em uma relação histórica de lutas e processos de evolução que envolve os indivíduos, destacando-se que essa luta não foi e não será em vão.

\section{REFERÊNCIAS}

BAUER, Lauren. A crise do COVID-19 já deixou muitas crianças com fome na América. Disponível em: <https://www.brookings.edu/blog/up-front/2020/05/06/the-covid-19-crisishas-already-left-too-many-children-hungry-in-america/>. Acesso em: 07 maio 2020.

BRASIL. Constituição da República Federativa do Brasil de 1988. Disponível em: <http://www.planalto.gov.br/> Acesso em: 20 jul. 2020.

Lei $\mathbf{n}^{\mathbf{0}} \mathbf{1 3 . 9 8 2}$ de 02 de abril de 2020. Disponível em: <http://www.planalto.gov.br/> Acesso em: 20 jul. 2020.

Lei $\mathbf{n}^{\mathbf{0}}$ 13.987, de 07 de abril de 2020. Disponível em: <http://www.planalto.gov.br/> Acesso em: 20 jul. 2020

Ministério da Saúde. Planos de Contingência Nacional para Infecção Humana pelo novo coronavírus COVID-19. 2020. Disponível em: 〈www.saude.gov.br/bvs〉. Acesso em: 20 jul. 2020.

CAETANO, Jose Eduardo Severino. Covid-19 frente ao estado democrático de direito e os direitos fundamentais. Disponível em: https://jus.com.br/artigos/81101/covid-19-frente-aoestadodemocratico-de-direito-e-os-direitos-fundamentais. Acesso em: 04 ago. 2020.

CASTRO, A. M. de (org.). Fome: um tema proibido. Rio de Janeiro: Civilização Brasileira, 1984.

CHADE, J. Brasil passa a ser $3^{\circ}$ maior exportador agrícola, mas clima ameaça futuro. $\mathbf{O}$ Estado de S. Paulo, São Paulo, 17 set. 2018. Disponível em:

https://economia.estadao.com.br/noticias/geral,brasil-passa-a-ser-3-maior-exportador-agricolamas-clima-ameaca-futuro,70002506105. Acesso em: 21 out. 2018.

FAO. Após três anos a fome mundial ainda não diminuiu e a obesidade continua crescendo. Disponível em: http://www.fao.org/news/story/pt/item/1201994/icode/. Acesso em 31 mar. 2021.

FERNANDES, Antonio Tadeu. Ministério da Saúde lança plano de contingência contra o Coronavírus. 2020. Disponível em: https://www.ccih.med.br/ministerio-da-saude-lancaplano-de-contingencia-contra-coronavirus/. Acesso em 30 jul.2020. 
FOOD AND AGRICULTURE OF ORGANIZATION OF THE UNITED STATES (FAO). El Estado de Seguridad Alimentaria y la Nutrición en el Mundo. 2018. Disponível em: http://www.fao.org/3/I9553ES/i9553es.pdf. Acesso em: 3 jan. 2019.

FREITAS, M. C. S. Agonia da fome [online]. Rio de Janeiro: Fiocruz; Salvador: EDUFBA, 2003. Disponível em: http://books.scielo.org. Acesso em: 9 fev. 2017.

GARCIA, M. F. A cada 4 segundos uma pessoa morre de fome no mundo. Disponível em: http://observatorio3setor.com.br/noticias/cada-4-segundos-uma-pessoa-morre-de-fome-nomundo/. Acesso em: 24 mar. 2017

IBGE. PNAD: Insegurança alimentar nos domicílios cai de 30,2\% em 2009 para 22,6 em 2013. Disponível em: https://agenciadenoticias.ibge.gov.br/agencia-sala-de-imprensa/2013agencia-de-noticias/releases/14735-asi-pnad-inseguranca-alimentar-nos-domicilios-cai-de302-em-2009-para-226-em-2013. Acesso em: 24 out. 2018.

MARANHÃO, J. Desafio à fome. São Paulo: Fulgor, 1962.

MELO, M. M.; NEVES, T. C. W. (org.). Josué de Castro. Brasília, DF: Plenarium, 2007. (Perfis Parlamentares, n. 52). Disponível em: file://C:/Users/Cliente/Downloads/perfis_josue_castro.pdf. Acesso em: 14 mar. 2017.

NASCIMENTO, R. C. A fome como uma questão social nas políticas públicas brasileiras. Revista IDeAS - Interfaces em Desenvolvimento, Agricultura e Sociedade, Rio de Janeiro, v. 3, n. 2, p. 197-225, jul./dez. 2009.

\section{O papel do Consea na construção da Política e do Sistema Nacional de}

Segurança Alimentar e Nutricional. Tese (Doutorado em Ciências Sociais em Desenvolvimento, Agricultura e Sociedade) - UFRRJ, Rio de Janeiro, 2012.

ONUBR. Uma a cada oito pessoas no mundo ainda passa fome. Brasília, DF, 2012.

Disponível em: https://nacoesunidas.org/uma-a-cada-oito-pessoas-no-mundo-ainda-passafome-alerta-estudo-da-onu/. Acesso em: 29 jan. 2019.

ONUBR. FAO: fome aumenta no mundo e afeta 821 milhões de pessoas. Brasília, DF, 2018. Disponível em: https://nacoesunidas.org/fao-fome-aumenta-no-mundo-e-afeta-821-milhoesde-pessoas/. Acesso em: 25 fev. 2019.

ONU News. Pandemia pode duplicar números de pessoas que enfrentam crises alimentares. 2021. Disponível em: https://news.un.org/pt/story/2020/04/1711102. Acesso em 31 mar. 2021.

OXFAM Brasil. Mais pessoas morrerão de fome no mundo do que de covid-19. Risco de disparada da fome no Brasil, 2020. Disponível em https://www.oxfam.org.br/noticias/maispessoas-morrerao-de-fome-no-mundo-do-que-de-covid-19-em-2020/. Acesso em 31 mar. 2021. 
PAINEL coronavírus, 2021. Disponível em: https://covid.saude.gov.br/. Acesso em 01 abr. 2021.

PELLANDA, Andressa. Covid-19, o novo coronavírus. 2020. Disponível em:

https://media.campanha.org.br/acervo/documentos/COVID-19_Guia1_FINAL.pdf. Acesso em: 20 jul. 2020.

PODESTÁ, O. P. G. de. Programa Bolsa de Família e a Segurança Alimentar e

Nutricional: o caso do município de Anchieta-ES. 2011. 139 f. Dissertação (Mestrado em Políticas Públicas e Desenvolvimento Local) - EMESCAN, Vitória, 2011.

RANGEL, T. L. V. Poder de polícia e segurança alimentar e nutricional: tessituras à vigilância sanitária e a função fiscalizadora de produtos e serviços de alimentos. 2016. Disponível em: http://www.conteudojuridico.com.br. Acesso em: 14 mar. 2019.

Fome: segurança alimentar e nutricional em pauta. Curitiba: Appris, 2018a.

Segurança Alimentar e Nutricional na Região Sudeste. Encontros, Desencontros e vulnerabilidades. 2018. 546 f. Tese (doutorado) - Programa de Pós-graduação em Sociologia e Direito. Universidade Federal Flunimense, Rio de Janeiro, 2018b.

RIBAS, L. F. de O. Alimentação, um "direito"? A institucionalização do direito humano à alimentação adequada no ordenamento jurídico brasileiro. Revista do Curso de Direito da UniAbeu, Rio de Janeiro, v. 1, p. 47-56, 2011.

SALES, Ana Paula Dias Messias. A Lei 13.979/29: uma garantia do direito à vida e a saúde pública em tempos de covid-19. 2020. Disponível em:

https://ambitojuridico.com.br/cadernos/direito-constitucional/a-lei-13-979-29-uma-garantiado-direito-a-vida-e-a-saude-publica-em-tempos-de-covid-19. Acesso em: 04 ago. DE 2020.

SEN, A. Desenvolvimento como liberdade. Tradução de Laura Teixeira Motta. São Paulo: Companhia das Letras, 2010.

A ideia de justiça. São Paulo: Companhia das Letras, 2011.

SERRANO, Pablo Jiménez. Doutrina dos direitos humanos. Rio de Janeiro: Jurismestre, 2016.

SILVA, T. E. M. da. Josué de Castro e os estudos sobre a fome no Brasil. Cronos, Natal, v. 10, n. 1, p. 51-57, jan./jul. 2009. Disponível em:

https://periodicos.ufrn.br/cronos/article/viewfile/1767/pdf_18. Acesso em: 9 fev. 2017.

VILLAS BÔAS, R. V.; SOARES, D. da S. O direito humano à alimentação adequada. Actas del II' Congreso Internacional de Derechos Humanos. Chile: Ribicón Editores, 2017.

VILLAS BÔAS, Regina Vera. No centro das preocupações com o desenvolvimento sustentável estão os seres humanos que têm direito à vida saudável e produtiva, construída em 
harmonia com a natureza. In: Angela Jank Calixto. (Org.). Meio ambiente \&

Desenvolvimento: Os 25 anos da Declaração do Rio de 1992. 1ed.São Paulo: Edição Instituto de Desenvolvimento Humano Global (IDG), 2018, v. 1, p. 34-52)

Capítulo: Erradicar a pobreza é acabar com a pobreza em todas as suas formas e em todos os lugares: Objetivo n. 1 do Desenvolvimento Sustentável (ODS). Obra Coletiva Direitos humanos e meio ambiente: os 17 objetivos de desenvolvimento sustentável da agenda 2030 [recurso eletrônico] / coordenação: Lívia Gaigher Bósio Campello. 1 ed. - São Paulo: IDHG (Instituto de Desenvolvimento Humano Global), 2020, p. 42 a 58 (ISBN 978-8585331-01-6).

ZIEGLER, J. Destruição em massa: Geopolítica da Fome. São Paulo: Cortez, 2013.

Especuladores devem ser julgados pela fome! 2013b. Disponível em:

http://www.teleios.com.br/especuladores-devem-ser-julgados-pela-fome-por-jean-ziegler/. Acesso em: 24 out. 2018. 